\title{
Rehabilitation of spinal cord injured patients on long term ventilation
}

\author{
J C Chawla MB BS FRCS MD \\ Clinical Director Welsh Spinal and Neurological Rehabilitation Unit, Rookwood Hospital, \\ Fairwater Road, Cardiff CF5 2YN, Wales.
}

\begin{abstract}
Recent advances in roadside management and resuscitation techniques have resulted in an increased survival rate of people with high cervical cord injury. A few become partially or permanently ventilator dependent. Not only are these people dependent on assisted ventilation, but their speech is also compromised, along with loss of voluntary control and many other bodily functions, as they are tetraplegic.

By using recent technological advancements, such as portable ventilators, phrenic nerve stimulation, environmental controls and specialised wheelchairs it has been possible to manage such patients at home. Furthermore, patients on ventilators are unable to have verbal communication. There is therefore a need for them to develop either augmentative communication or the use of alternative communication aids. Recent published reports indicate the factors other than the clinical state that may prevent such patients from taking advantage of modern advances; the main issues appear to be cost factors, community care provision and ethical considerations.
\end{abstract}

Keywords: assisted ventilation; domiciliary ventilation; tetraplegia; mobility; communication; rehabilitation.

\section{Introduction}

The early mortality due to respiratory insufficiency of patients with cervical spinal cord injury has been reported to be 4.7 to $40 \% .{ }^{1-4}$ Recent advances in emergency and acute management has resulted in the survival of increasing numbers of patients with high cervical cord injury. They may have paralysis of their main inspiratory and all of their expiratory muscles, and require assisted ventilation. Most of those on a ventilator later breathe spontaneously, even although respiratory function remains impaired and the vital capacity is $60 \%$ of normal. ${ }^{5,6}$ There are a small number of patients, who remain ventilator dependent either totally or incompletely. ${ }^{7}$ Experience has shown that an early transfer to an appropriate spinal unit of patients who remain dependent on a ventilator ${ }^{8}$ will lead to the successful return of the patients to the

Paper read at the first European Conference on Domiciliary Ventilation and High Spinal Cord Lesion in Southport, England, in October 1991. community. Even if the spinal unit is not fully equipped and staffed to deal with such patients, contact should be made as it will help with planning the needs of the patients. This paper, based on an experience of 8 patients who required long term assisted ventilation suggests a realistic approach to rehabilitation.

\section{Patients and results}

All but one patient were discharged home and some of the clinical information is summarised in Table I.

\section{Discussion}

The availability of advanced technology, good care programmes and dedication of the family has enabled the majority of ventilation dependent patients to return to an environment of their own choosing. Survival of such patients raises many issues - medical, physical, social, psychological, 
Table I

\begin{tabular}{|c|c|c|c|c|c|c|}
\hline No. & Sex & $\begin{array}{l}\text { Age at } \\
\text { injury }\end{array}$ & $\begin{array}{c}\text { Neurological } \\
\text { level }\end{array}$ & $\begin{array}{l}\text { Diaphram } \\
\text { pacing }\end{array}$ & Follow up & Outcome \\
\hline 1 & M & 46 yrs & $\mathrm{C} 3$ & - & 25 years & Hospital in patient \\
\hline 2 & $\mathrm{~F}$ & 59 yrs & $\mathrm{C} 2$ & - & - & Died on initial admission \\
\hline 3 & $\mathrm{~F}$ & 2 yrs & $\mathrm{C} 2$ & - & 24 months & Moved from area \\
\hline 4 & $\mathrm{M}$ & 22 yrs & $\mathrm{C} 3$ & Not suitable & 24 months & Died at home \\
\hline 5 & $\mathrm{M}$ & 8 yrs & C3 & Yes & 36 months & Died at home \\
\hline 6 & $\mathrm{~F}$ & $4 \mathrm{yrs}$ & $\mathrm{C} 2 / 3$ & Not suitable & 48 months & At home \\
\hline 7 & $\mathrm{M}$ & 32 yrs & $\mathrm{C} 4$ & Not suitable & 36 months & At home not on ventilator \\
\hline 8 & $\mathrm{M}$ & $41 \mathrm{yrs}$ & $\mathrm{C} 3 / 4$ & Not suitable & 24 months & At home \\
\hline
\end{tabular}

and ethical - which require careful consideration. A patient with a high cervical spinal injury not only requires management of the bony injury and its consequences but may also require assisted ventilation. Most of the patients can be weaned off the respirator. A successful weaning programme requires increasing time off the ventilator and a progressive muscle strengthening programme. ${ }^{9}$ Success of weaning depends upon physiological stability and psychological readiness $^{10}$ and the techniques of weaning should be tailored to the individual patient. ${ }^{8}$ Use of rocking beds and pneumobelts has proved to be of value in the process of weaning; ${ }^{11,12}$ we have no experience of these techniques. Even although the efforts are energy consuming and stressful to the patient, every effort should be made to wean the patient off the ventilator. It is felt that if weaning cannot be achieved, short periods off the ventilator should be attempted for safety and psychological reasons. ${ }^{13}$

If patients cannot be weaned off the respirator, careful consideration should be given for diaphragm pacing. Lesions above C3 normally leave the anterior horn cells to the phrenic nerves viable and therefore these nerves have the potential to be stimulated electrically. The technique of diaphragm pacing by stimulating the intact phrenic nerve has permitted some ventilator dependent patients to become free of the respirator. ${ }^{14,15}$ It has been suggested that phrenic nerve conduction studies in the early days following injury may give a false negative response to stimulation, and that consideration for surgical implants should be delayed for 6-12 months post injury. ${ }^{15}$ Furthermore, not all patients are suitable. Only one out of 5 patients was suitable for diaphragm pacing.

The ability to communicate in a meaningful context is an integral part of human relationships. Communication enables the individual to share experiences, define needs, and express wishes and emotions. A ventilator dependent patient is either intubated or has a tracheostomy and is deprived of the ability to communicate verbally. They are usually on cervical traction, have restricted neck movements and are virtually 'locked in'. As oral communication is not possible at this stage, alternative systems need to be developed as early as possible to enable the patients to make others aware of their physical and emotional needs. Initially eye movement or blinking may be used to indicate yes or no. When head and neck movements are permissible, some form of low technique scanning systems can be established. Communication is by selecting alphabets, items or words from a board by using a head or mouth pointer. Such an approach will allow patients to communicate even though they are not able to initiate conversation. As the clinical condition stabilises, techniques to develop oral communication should be explored. By deflating the cuff and increasing the tidal volume, the patient can learn to speak without inspiration. The patient also needs to learn to swallow saliva to avoid aspiration. In the presence of a cuffed tracheostomy, provision of a speaking tube will permit oral communication. If the patient can be free of the ventilator for a period of time, a 
fenestrated tracheostomy tube which permits speech can be used. ${ }^{16}$ To discuss alternative or augmentative speech in detail is beyond the scope of this paper. Early discussion with a speech and language therapist will help to develop some form of communication. Independence of communication cannot be overstressed as it is the only way by which the ventilator dependent spinal cord injured person can interact, define needs and exercise autonomy.

Mobility and assuming the upright position is the single most important factor in reducing respiratory complications. ${ }^{10}$ Establishment of early mobility, when permitted by the stability of the bony injury, will enable the patient to establish contact with the environment in and outside the intensive care unit and decrease physical and environmental isolation. Patients 1 and 3 had extreme difficulty in moving away from the intensive care unit. The wheelchair prescription requires careful consideration, not only concerning mobility - indoor and out door but also regarding ventilator and other equipment. The ability to control a wheelchair enables the patient to control other devices. Specific areas which need to be taken into account are adaptations for ventilator, wheelchair controls, posture and stability of the patient and systems to control the environment. Early introduction of equipment gives a psychological boost to the patient. ${ }^{13}$ Patient 1 was introduced to the spinal unit about 8 months after injury and had great difficulty in accepting the type of equipment which was suggested. Even if the specialised unit is unable to accept an acute ventilator dependent patient, early involvement in a spinal unit will allow for better total management and the planning of a reasonable and cost effective package of care. ${ }^{13}$ This is borne out by our own experience. It is, therefore, suggested that early contact with a spinal unit should be established even if the unit is not in position to admit the patient in the acute stage. Careful consideration and discussions about discharge plannning need to begin as soon as possible and must include the patient, relatives and statutory bodies. The areas of concern that require address are: supply, funding and maintenance of equipment; care required and its provision; housing requirements; vocational, educational and leisure needs; and continued support and follow up. As the patient is mobilised, his or her carers need to learn the techniques of transfer and skills for providing care, preventing complications of spinal cord damage. Caring for a person with a severe disability imposes considerable stress on the family. The patient and the family should be made aware of this at an early stage, including implications for the future. ${ }^{17}$ Information about the disability should be given in such a manner that it does not destroy hope. ${ }^{18}$ Continued dependence on a ventilator may preclude the family from providing care as they may be afraid to take the patient home. There may be a denial process which prevents the family facing up to implications for the future. The family should be involved at all stages of management and planning for the future. When the family members are available, capable and willing to provide care, the cost is obviously going to be lower in economic terms but it may be high in emotional and psychological terms. With suitable support, a ventilator dependent spinal cord injured patient can be discharged home. ${ }^{8,19}$ Patient 6 is being cared for by employed and trained staff at a considerable cost to the authorities and the family is coping with the situation much better than that of patient 8 whose wife eventually left him. He is dependent on his brother and appears to be well settled in the community. The father of patient 5 gave up work to provide care.

It appears that there are a group of patients who develop respiratory insufficiency some years after high cervical injury. ${ }^{20}$ We have had 3 such patients, one of whom died during sleep. It appears that patients who are obese, have upper airway obstruction and/or have chronic pulmonary obstructive disease are prone to develop respiratory failure. Such patients are difficult to arouse and may complain of headaches.

Other symtoms which may be present are: restless sleep; morning confusion; daytime sleepiness; weak cough; difficulty in speaking continuously; and apparent mental dulling. These symptoms are considered to be 
due to nocturnal hypoxia and raised $\mathrm{PCO} 2$ because of the decrease in rate and volume of respiration during sleep. Overnight oximetry, measurement of awake and resting arterial blood gases and vital capacity in the sitting and lying supine position will help identify patients who are suffering from sleep apnoea. As the vital capacity is lower lying supine than it is sitting, and the functional residual capacity is greater when lying on the side, the patient will benefit by sleeping propped up and/or side lying. ${ }^{21,22}$ Overnight ventilation can reverse the blood gases resulting in the resolution of symptoms. One of our surviving patients requires overnight ventilation. It is suggested that non ventilator dependent high cervical spinal cord injured patients should have their vital capacity and forced expiratory volume assessed on a regular basis. Reduction in the forced expiratory volume may indicate development of obstructive lung disease in these patients who already have restricted pulmonary function.

Ventilator dependent spinal cord injured patients present complicated medical, social and ethical problems. The ethical issues are considerable and are concerned with resources and autonomy. ${ }^{23,24}$ The cost of equipping and maintaining ventilator patients are considerable and many such patients may come from health authorities other than the one supporting the intensive care and spinal unit.

\section{Acknowledgement}

I wish to record my thanks to Dr Colin Wise and other colleagues who were concerned with the management of these patients. Their input is greatly appreciated.

\section{References}

1 Tribe CR (1963) Causes of death in the early and late stages of paraplegia. Paraplegia 1: 19-46.

2 Guttmann L, Silver JR (1965) Electromygraphic studies on reflex activity of the intercostal and abdominal muscles in cervical cord lesions. Paraplegia 3: 1-22

3 Bellamy R, Pitts FW, Shannon Stauffer E (1973) Respiratory complications in traumatic quadriplegia. Analysis of 20 years experience. J Neurosurg 39: 596-600.

4 Carter RE (1980) Unilateral diaphragmatic paralysis in spinal cord injured patients. Paraplegia 18: $267-273$.

5 Forner JV (1980) Lung volumes and mechanics of breathing in tetraplegics. Paraplegia 18: 258-266.

6 Fugl-Meyer AR, Grimby G (1971) Ventilatory function in tetraplegic patients. Scand J Rehabil Med 3: $151-160$.

7 Wicks AB, Menter RR (1985) Longterm outlook in quadriplegic patients with initial ventilation dependency. Chest 86: 415-420.

8 Gardner BP, Watt JHW, Krishnan KR (1986) Artificial ventilation of acute spinal cord damaged patients. Paraplegia 24: 208-220.

9 Gross D, Ladd HW, Riley EJ, Macklem PT, Grasino A (1980) The effect of training on strength and endurance of the diaphragm in quadriplegia. Am J Med 68: 27-35

10 Roper E (1977) Consideration of respiratory function in cervical cord injuries. Paper presented in Englewood, Colorado.

11 Weingarden SI, Belen JG (1987) Alternative approach to the respiratory management of the high cervical spinal cord injury patient. Int Disabil Studies 9: 132-133.

12 Miller HJ, Thomas E, Wilmot CB (1988) Pneumobelt use among high quadriplegic population. Arch Phys Med Rehabil 69: 369-372.

13 Dingermans LM, Hawn JM (1978-79) Mobility and equipment for ventilator-dependent tetraplegics. Paraplegia 16: 175-183.

14 Glenn WWL, Hogan JF, Phelps MS (1980) Ventilatory support of the qaudriplegic patient with respiratory paralysis by diaphragm pacing. Surg Clin North Am 60: 1055-1078.

15 Leiberman JS, Corkhill G, Nayak NN, French BN, Taylor RG (1980) Serial phrenic nerve conduction studies in candidates for diaphragm pacing. Arch Phys Med Rehabil 61: 528-531.

16 Kirby NA (1989) The individual with high quadriplegia. Nurs Clin N Am 24: 1: 179-191.

17 Harris P, Patel S, Greer W, Naughton J (1973) Psychological and social reactions to acute spinal paralysis. Int J Paraplegia 11: 132-136.

18 Caywood T (1974) A quadriplegic young man looks at treatment. J Rehabil 49: 22-25.

19 Furhrer MJ, Carter RE, Donovan WH, Rossi CD, Wilkerson MA (1987) Post discharge outcomes for ventilator-dependent quadriplegics. Arch Phys Med Rehabil 68: 353-356.

20 Polatty RC 1983) Signs and symptoms in pulmonary medicine. In: Glausser FL, editor. Muscles of Respiration. JB Lippincot, Philadelphia: 107-124. 
21 Efthimiou J, Fleming J, Spiro SG (1987) Sternomastoid muscle function and fatigue in breathless patients with severe respiratory disease. Am Rev Respir Dis 136: 1099-1105.

22 Rochester DF, Braun NMT, Laine S (1977) Diaphragmatic energy expenditure in chronic respiratory failure. The effect of assisted ventilation with body respirators. Am J Med 63: 223-232.

23 Maynard FM, Muth AS (1987) Choice to end life as a ventilator-dependent quadriplegic. Arch Phys Med Rehabil 68: 862-864.

24 Purtilo RB (1986) Ethical issues in the treatment of chronic ventilator-dependent patients. Arch Phys Med Rehabil 67: 718-721. 